\title{
A new anatomic zone division within the human cervical spinal canal
}

Chao Kong

Capital Medical University

Li Liu

Capital Medical University

Yadong Liu

Capital Medical University

Xin Yuan

Capital Medical University

Yan Gao

Capital Medical University

Yun Guan

Johns Hopkins University

Xueming Chen ( $\nabla$ xuemingchen@sina.com )

\section{Research article}

Keywords: cervical spondylosis; ventral nerve rootlets; morphology; anatomic zone.

Posted Date: July 1st, 2020

DOI: https://doi.org/10.21203/rs.2.21245/v3

License: (c) (1) This work is licensed under a Creative Commons Attribution 4.0 International License.

Read Full License 


\section{Abstract}

Background: Anatomic details are important for identifying the origin and anatomic basis of symptoms in patients with cervical spondylosis. However, very little quantitative data has been reported. In an effort to provide an anatomic basis for the examination of cervical spondylosis mechanisms, we characterized the morphologic features of cervical spinal nerve rootlets and defined different zones of the human cervical spinal canal.

Methods: In 10 cadaveric cervical cords from C2 to T1, we defined three zones bilaterally from the midline (zones I-III) and two zones from cranial to caudal (zones P and IP) on the coronal plane within the cervical spinal canal. We measured each anatomic zone, including 1) horizontal widths of zones I, II and III; 2) the length of the cervical spinal segment at the ventral rootlets (LV); 3 ) the pedicle height (zone P) and interpedicle height (zone IP); and 4) the distance between the superior margin of the pedicle and the exit of the uppermost ventral nerve rootlet (PN).

Results: The horizontal widths of zone I tended to decrease gradually from C4 to C8 ( $p=0.98)$. The width of zone II at C4 was significantly less than that at other levels $(p=0.008)$. The width of zone III increased from $\mathrm{C} 4$ to $\mathrm{C} 8$ and was significantly greater at $\mathrm{C} 7$ and $\mathrm{C} 8$ than at $\mathrm{C} 4, \mathrm{C} 5$, and $\mathrm{C} 6(p=0.032)$. Pedical and interpedical heights were not significantly different at different levels ( $p=0.365$ and 0.240 , respectively). $\mathrm{LV}$ values at $\mathrm{C} 4$ and $\mathrm{C} 8$ were smaller than those at $\mathrm{C} 5, \mathrm{C} 6$, and $\mathrm{C} 7(p=0.001)$. At $\mathrm{C} 4$, the uppermost ventral rootlet was at approximately the same height as the $\mathrm{C} 3$ pedicle, whereas at $\mathrm{C} 8$, the uppermost ventral rootlet was at the same level as the inferior part of the $\mathrm{C} 6$ pedicle. Ventral intradural intersegmental connections were found in three of 20 (15\%) intersegments (two specimens).

Conclusions: These anatomic zones may be useful for diagnosing cervical spondylosis and guiding anterior decompression surgery.

\section{Background}

Cervical spondylosis is often caused by degenerative disc disease that may lead to neck pain, radiculopathy, and myelopathy [1-3]. Theoretically, cervical radiculopathy is due to compression of the nerve roots, whereas cervical myelopathy results from compression of the spinal cord. Patients with radiculopathy and myelopathy often have distinct syndromes [4], making diagnosis of the pathogenesis relative easy. In contrast, diagnosing myeloradiculopathy is more challenging, as patients may show complicated syndromes, including signs of nerve root dysfunction in the upper limbs and symptoms of long tract compression in the lower limbs.

The pathogenic mechanisms of myeloradiculopathy remain unclear, and it has been difficult to ascertain whether the dysfunctions are due to compression of the nerve root and/or the spinal cord [5]. In particular, patients with cervical radiculopathy may have various symptoms without clear nerve root location. Anatomic differences in the brachial plexus may partially underlie the large variation in clinical symptoms of patients with cervical radiculopathy [6]. Because adjacent rootlets may have intradural intersegmental 
connections, compression of one rootlet can lead to impairments at adjacent rootlets, leading to more symptoms [7]. A previous study showed an increased obliquity of nerve roots, especially in the lower cervical region, when these roots pass downward before reaching the intervertebral foramina [8]. Accordingly, it has been difficult to ascertain whether the nerve roots are compressed above or at the corresponding disc level in imaging studies.

Detailed anatomic information of the cervical spinal cord and nerve roots is important for identifying the origin and anatomic basis of symptoms in patients with cervical spondylosis. Such data are essential for using surgical intervention to decompress the affected neural structures and avoid complications. By dissecting cervical spinal cord of adult cadavers, we characterized the morphologic features of cervical spinal nerve rootlets and defined different zones at the cervical spinal canal. Our findings provide an anatomic basis for future study to differentiate subtypes of cervical spondylosis and examine the underlying mechanisms.

\section{Methods}

Cervical spines were harvested from 10 formalin-fixed adult cadavers ( 6 males, 4 females; mean age $=67$ \pm 12.1 years) without cervical metastasis or gross deformities such as scoliosis or kyphosis. These cadavers were obtained from the Department of Human Anatomy, Capital Medical University, China. The research protocol for this study was approved by the Institutional Review Board at LuHe Hospital, Capital Medical University.

\section{Cadaveric dissections}

The cervical spines were fixed in the supine position. Soft tissues superficial to vertebrae were removed. The vertebral bodies and anterior tubercle of the transverse process were resected completely from C3 to C7. The posterior longitudinal ligament from the anterior dura was then resected with caution. The dura and arachnoid membrane were excised carefully from C4 to C8 without damaging the spinal cord and ventral (anterior) nerve rootlets. The anterior part of the nerve root sleeves was also resected to provide an unobstructed view of the ventral nerve rootlets (Figure 1).

\section{Anatomic zones in the coronal plane}

In the coronal plane, the anterior surface of the spinal canal was divided into three zones bilaterally from the midline: zone I (medial zone), zone II (paramedian zone), and zone III (lateral zone) (Figure 2). Zone I represents the area between bilateral origins of the ventral nerve rootlet. Zone II contains the area between the origin of the ventral nerve rootlets and the lateral border of spinal cord. Zone III represents the area between the lateral border of the spinal cord and the medial margin of the pedicle. Two zones were defined from cranial to caudal: the pedicle zone (zone P) and interpedicle zone (zone IP). Zone P defines the area between the upper and lower margins of the corresponding pedicle, which contains the major part of the corresponding spinal cord segment and ventral nerve rootlets. Zone IP includes the area between the lower margin of the upper pedicle and the upper margin of the lower pedicle, which contains 
the caudal part of the corresponding spinal cord segment and ventral nerve rootlets as well as the cranial part of the inferior segmental spinal cord and the ventral nerve rootlets (Figure 2).

\section{Parameters}

Measurements of the anatomic structures from C4 to C8 included 1) horizontal widths of zones I, II, and III (Figure 2);2) length of the cervical spinal cord segment at the ventral rootlets (LV, Figure 2); 3 ) the pedicle height (zone P) and the interpedicle height (zone IP, Figure 2); and 4) the distance between the superior margin of the pedicle and the exit of the uppermost ventral nerve rootlet (PN, Figure 2). All measurements were made bilaterally, and the mean values are reported. The widths of zones I, II, and III were measured at three different levels (uppermost, middle, lowermost) and the mean values were used for comparison. The linear measurements were obtained with a digital caliper. All parameters were measured twice by two researchers.

\section{Statistical analysis}

The differences between parameters measured at different levels were compared by one-way analysis of variance (ANOVA) with LSD (least significant difference) post-hoc test. All statistical analyses were conducted with SPSS 21.0 (IBM Corp, Armonk, NY). Data are presented as mean \pm standard deviation (SD), and the statistical significance was set as $p<0.05$.

\section{Results}

\section{Horizontal widths of zones I, II, and III}

The horizontal widths of zone I showed a trend toward a gradual decrease from C4 to C8 (Table 1). However, the they were not significantly different between different levels $(F=2.157, p=0.98)$. The width of zone II at C4 was significantly less than that at other levels $(\mathrm{F}=4.228, p=0.008)$. The width of zone III increased from $\mathrm{C} 4$ to $\mathrm{C} 8$, and the widths at $\mathrm{C} 7$ and $\mathrm{C} 8$ were significantly greater than those at $\mathrm{C} 4, \mathrm{C} 5$, and C6 $(F=3.050, p=0.032)$. An example of zone division with the neural structures is illustrated in Figure 3. After the vertebral body and intervertebral disc were removed, compressions at zone I and zone II were identified in two samples (Figure 4).

Table 1. The horizontal widths of zone I, II and III from C4 to C8 (mm)

\begin{tabular}{llllll}
\hline & C4 & C5 & C6 & C7 & C8 \\
\hline zone I & $6.11 \pm 0.63$ & $5.58 \pm 0.49$ & $5.69 \pm 0.59$ & $5.45 \pm 0.62$ & $5.11 \pm 0.62$ \\
\hline \multirow{2}{*}{ zone II } & $2.35 \pm 0.61 * *$ & $3.34 \pm 0.56$ & $3.56 \pm 0.68$ & $3.73 \pm 0.61$ & $3.51 \pm 0.69$ \\
\hline \multirow{2}{*}{ zone III } & $4.22 \pm 0.57$ & $4.49 \pm 0.68$ & $4.98 \pm 0.68$ & $5.01 \pm 0.82^{*}$ & $5.21 \pm 0.76^{*}$ \\
\hline
\end{tabular}

Note: Zone I: There was no significant difference in horizontal width between different levels. Zone II: ** $\mathrm{p}<0.01$ versus C 5,6,7,8. Zone III: * $p<0.05$ versus C 4, 5,6. 
The pedicle height and the interpedicle height were measured to represent the longitudinal heights of zone $\mathrm{P}$ and zone IP (Table 2). Pedical and interpedical heights did not differ significantly between different levels (pedical: $\mathrm{F}=1.121, p=0.365$; interpedical: $\mathrm{F}=1.458, p=0.240$ ).

Table 2. The pedicle height $(\mathrm{PH})$ and the interpedicle height (IPH) from $\mathrm{C} 3$ to $\mathrm{C} 7(\mathrm{~mm})$

\begin{tabular}{llllll}
\hline & $\mathrm{C} 3(\mathrm{C} 3 / 4)$ & $\mathrm{C} 4(\mathrm{C} 4 / 5)$ & $\mathrm{C} 5(\mathrm{C} 5 / 6)$ & $\mathrm{C} 6(\mathrm{C} 6 / 7)$ & $\mathrm{C} 7(\mathrm{C} 7 / \mathrm{T} 1)$ \\
\hline $\mathrm{PH}$ & $7.9 \pm 0.88$ & $8.52 \pm 1.1$ & $8.18 \pm 1.26$ & $8.53 \pm 1.29$ & $9.12 \pm 1.16$ \\
\hline $\mathrm{IPH}$ & $8.15 \pm 1.09$ & $8.29 \pm 0.94$ & $7.85 \pm 1.88$ & $7.23 \pm 0.46$ & $7.17 \pm 0.77$ \\
\hline
\end{tabular}

Note: C3(C3/4) means PH of C3 and IPH of C3/4. PH, pedicle height; IPH, interpedicle height.

\section{Longitudinal length of the cervical spinal cord segment at ventral rootlets}

The mean length of LV in millimeters was $10.92 \pm 1.95$ at $C 4,14.64 \pm 2.33$ at $C 5,13.27 \pm 1.33$ at $C 6$, $12.30 \pm 1.48$ at $\mathrm{C} 7$, and $10.28 \pm 2.09$ at $\mathrm{C} 8$. The values of $\mathrm{LV}$ at $\mathrm{C} 4$ and $\mathrm{C} 8$ were smaller than those at $\mathrm{C} 5$, $\mathrm{C} 6$, and $\mathrm{C7}(\mathrm{F}=6.177, p=0.001)$.

\section{Anatomic relation between the segmental ventral rootlets and pedicle}

The distance between the superior margin of the pedicle and the uppermost ventral rootlet (PN) was measured to reflect the relative position of segmental ventral rootlets and pedicle. PN (in millimeters) was $0.33 \pm 0.87$ at $\mathrm{C} 3,3.86 \pm 2.23$ at $\mathrm{C} 4,4.11 \pm 2.36$ at $\mathrm{C} 5,3.94 \pm 2.18$ at $\mathrm{C} 6$, and $5.19 \pm 2.09$ at $\mathrm{C} 7(\mathrm{~F}=5.809$, $p=0.001$ ). At $\mathrm{C} 4$, the uppermost ventral rootlet was at about the same height as the $\mathrm{C} 3$ pedicle, and the $\mathrm{C} 8$ uppermost ventral rootlet was at the same level as the inferior part of the $\mathrm{C} 6$ pedicle. The latter relationship may explain why some patients with compression at $\mathrm{C} 6 / 7$ have symptoms at $\mathrm{C} 8$.

\section{Ventral intradural intersegmental connections}

Ventral intradural intersegmental connections were found in 3 of 20 intersegments (15\%; in two specimens). One specimen had bilateral connections whereas the other had unilateral connections (Figure 5). Both connections were found in C5/6 segment between $\mathrm{C} 5$ and $\mathrm{C} 6$ ventral rootlets.

\section{Discussion}

Cervical spondylosis encompasses a variety of motor and sensory abnormalities, such as radiculopathy, myelopathy, and myeloradiculopathy. However, the radiological findings in many patients do not match well with their symptoms [5]. A better understanding of the anatomic basis of cervical spondylosis may help to uncover the reasons for this mismatch. Veleanu [9] initially divided the nerve groove into two portions-the radicular portion and the anterior ramus of the transverse process-but did not provide quantitative data. Ebraheim et al. [10] described the cervical nerve groove according to the different anatomic features along its length and divided the nerve groove into three zones: medial (pedicle), middle (vertebral artery), and lateral. The medial zone was suggested to play an important role in the etiology of cervical spondylotic radiculopathy [8]. However, this zone division was focused on the cervical nerve groove and did not include the spinal cord and ventral nerve rootlets within the spinal canal. 
To better understand the etiology of cervical spondylosis, which is important for obtaining an accurate diagnosis and decompressing the site, we defined three zones outward from the midline and two zones from cranial to caudal on the coronal plane. The coronal widths of zone I did not differ significantly at C4C8 levels. Since zone I contains only spinal cord and anterior spinal artery, localized compression in zone I may cause myelopathy without radiculopathy. Zone II contains cervical ventral nerve rootlet origins and the lateral border of the spinal cord. Compression in zone II may cause both myelopathy and radiculopathy. Ebraheim et al. [10] illustrated the importance of the nerve root groove, but not the preforaminal area, in the etiology of cervical spondylotic radiculopathy. Osteophytes of the posterolateral corner of the vertebral body, uncinated process, facet joints, and lateral intervertebral disc herniation are often observed in zone III [11]. In the preforaminal area, compression in zone III can be missed by clinical examination, leading to misdiagnosis and inadequate decompression.

Cervical spondylotic amyotrophy (CSA) is characterized by weakness and wasting of upper limb muscles without sensory or lower limb involvement [12-14]. The underlying mechanisms of CSA may involve damage to the ventral nerve rootlets and vascular insufficiency to the anterior horn cells. Accurate diagnosis of CSA and precise surgery require a detailed characterization and definition of different anatomical zones. Compression of zone I may cause anterior spinal artery impingement that leads to dysfunction of anterior horn cells, which may partially explain why a moderate compression of the central canal sometimes leads to CSA [13]. Compression at zone II will impair the ventral nerve rootlets and anterior horn of the spinal cord. As a result, such compression may cause motion dysfunction without sensation loss. The compression at zone III defined in our study may only impair the ventral nerve rootlets. Since zone III at $\mathrm{C} 6 / 7$ contains ventral nerve rootlets of $\mathrm{C} 7$ and $\mathrm{C} 8$, compression in this region may cause CSA at both levels (Figure 3). Thus, the definition of zone division is important to correct diagnosis of CSA and decompression of the ventral nerve rootlets.

The relationship between disc level and LV is important for estimating the corresponding disc level in neurological diagnosis. In this study, LV lengths at C4 and C8 were shorter than those at C5, C6, and C7. Although the difference appears subtle, it may have a clinical impact because the cervical canal area is very small. The distance between the superior margin of the pedicle and the uppermost ventral rootlet (PN) was also very important in the diagnosis. In our study, the uppermost ventral rootlet at C4 was at about the same height as the C 3 pedicle, and the C8 uppermost ventral rootlet was at the same level as the inferior part of the $\mathrm{C} 6$ pedicle. This spatial relationship may explain why some patients with compression at $\mathrm{C} 6 / 7$ show symptoms of $\mathrm{C} 8$.

The degree of spondylosis would affect the IP value. We should note, however, that the cadaveric cervical spines that we used had no cervical metastasis or gross deformities (e.g., scoliosis, kyphosis). We also avoided cadavers from patients with a history of cervical surgery or cervical spondylosis. Nevertheless, since the average age of this cohort was $67 \pm 12.1$ years, cervical degeneration may have occurred that could have affected the accuracy of the measurements. Early surgery is recommended to CSA patients who have not been helped by conservative treatments. The zone definition that we established may help in the diagnosis of CSA for early surgical intervention. 
To our knowledge, no study had examined the relative position of segmental ventral rootlet and pedicle. Here, we defined two zones in the coronal plane from cranial to caudal. At the C3 pedicle level, the segmental spinal cord and ventral nerve rootlets of $\mathrm{C} 4$ were at zone P. From C3 to C7, the position of segmental ventral rootlet and spinal cord became more rostral to the corresponding pedicle. For example, the segmental spinal cord and ventral nerve rootlets of $\mathrm{C} 8$ were near to the inferior part of the $\mathrm{C} 6$ pedicle. This finding may help to explain why patients with disc herniation at $\mathrm{C} 6 / 7$ could have symptoms from $\mathrm{C} 8$ nerve root compression. A previous study suggested that $\mathrm{C} 8$ nerve root does not contact the $\mathrm{C} 7-\mathrm{T} 1$ disc. Hence the chance of a direct C8 nerve root compression by the C7-T1 disc is very small [8]. However, our findings suggest that the chance of compression of $\mathrm{C} 8$ ventral nerve rootlets by $\mathrm{C} 6 / 7$ disc is rather large. Furthermore, compressions of zone I and zone II at C6/7 may also cause dysfunctions of C8 spinal cord and ventral nerve rootlets. However, compression at zone III may lead to radiculopathy of both $\mathrm{C} 7$ and $\mathrm{C} 8$ ventral nerve rootlets.

Anatomic studies have been conducted to evaluate the width of the spinal segment [15-17]. Shinomiya et al. [17] investigated the width of the spinal segment from C5 to C8 using cadavers and reported that C6 was the widest and C8 the narrowest. Kobayashi et al. [18] also confirmed that C8 was the narrowest, and this characteristic continued to the entry of the root in the foramen. Karatas et al. [16] measured the widths from $\mathrm{C} 2$ to $\mathrm{C} 8$ and found that the longest longitudinal length was at $\mathrm{C} 5$, whereas the shortest was at $\mathrm{C} 2$. We found that the longitudinal length of segmental ventral rootlets at $\mathrm{C} 4$ and $\mathrm{C} 8$ were shorter than those at $\mathrm{C} 5, \mathrm{C} 6$, and $\mathrm{C} 7$.

As shown in the study by Tanaka et al. [8], intradural intersegmental connections were rare in ventral rootlets (two connections out of 36 intersegments, $6 \%$ ) and much thinner. Both connections were found between $\mathrm{C} 4$ and $\mathrm{C} 5$ ventral rootlets. We found three connections (two specimens) out of 20 intersegments (15\%) (Figure 5). One specimen had bilateral connections and the other had unilateral connections. Both connections were found in the C5/ 6 segment between ventral rootlets of $\mathrm{C} 5$ and $\mathrm{C} 6$ and were relatively thinner than other bundles of the rootlets. These anatomic findings may also help to explain why some patients with cervical radiculopathy show diffusive symptoms with blurred nerve root location. Our study had some limitations. First, only a small number of cadavers were available. Additionally, those that were available were formalin-fixed, which may affect the accuracy of the measurements. Findings from our study will need to be confirmed in future studies that include a larger sample size and unfixed tissues.

\section{Conclusion}

A comprehensive understanding of neurologic anatomy in the cervical spinal canal is important for accurate diagnosis of cervical spondylosis. The division of the cervical spinal canal into different zones may be useful for diagnosis of cervical spondylosis and conducting safe and effective anterior decompression surgery. Additional studies are needed to correlate the anatomic zones defined in this study with radiologic findings and clinical symptoms in patients with cervical spondylosis. 


\section{List Of Abbreviations}

LV: length of the cervical spinal cord segment at the ventral rootlets; PN: distance between the superior margin of the pedicle and the exit of the uppermost ventral nerve rootlet; P: pedicle zone; IP: interpedicle zone; ANOVA: one-way analysis of variance; LSD: least significant difference; SD: standard deviation.

\section{Declarations}

1) Ethics approval and consent to participate: This study was approved by the Ethical committee of Beijing Luhe Hospital. Each participant gave written, informed consent to participate.

2) Consent for publication: Consent to publish potentially identifying information of patients was obtained.

3) Availability of data and materials: The datasets used and/or analyzed during the current study are stored in our hospital and are available from the corresponding author on reasonable request.

4) Competing interests: The authors declare that they have no competing interests.

5) Funding: This study was supported by a grant from the Science and Technology Commission of Tongzhou District.

6) Authors' contributions: C.K. conducted the dissection, took measurements, and wrote the first draft. L.L. took measurements and analyzed the data. Y.L. took measurements and helped with manuscript writing. X.Y. did the dissection. Y.G (Yun Guan) discussed the data and helped with manuscript writing. Y.G (Yan Gao) performed the statistical analysis. X.C. designed the study, directed the project, and wrote the final version of manuscript. All authors have read and approved the manuscript.

7) Acknowledgements: This study was conducted at Beijing Luhe Hospital, Capital Medical University. The authors thank International Science Editing (http://www.internationalscienceediting.com) for editing the first version of this manuscript and Claire F. Levine, MS (scientific editor, Department of Anesthesiology and Critical Care Medicine, Johns Hopkins University), for editing the final version of this manuscript.

\section{References}

1. Kim HJ, Tetreault LA, Massicotte EM, et al. Differential diagnosis for cervical spondylotic myelopathy: literature review. Spine (Phila Pa 1976). 2013;38: S78-S88.

2. Bono CM, Ghiselli G, Gilbert TJ, et al. North American Spine Society: An evidence-based clinical guideline for the diagnosis and treatment of cervical radiculopathy from degenerative disorders. Spine J. 2011, 11: 64-72. 
3. Shamji MF, Massicotte EM, Traynelis VC, et al. Comparison of anterior surgical options for the treatment of multilevel cervical spondylotic myelopathy: a systematic review. Spine (Phila Pa 1976). 2013, 38: S195-S209.

4. Lebl DR, Bono CM. Update on the Diagnosis and Management of Cervical Spondylotic Myelopathy. J Am Acad Orthop Surg. 2015, 23: 648-60.

5. McCormack BM, Weinstein PR. Cervical spondylosis. An update. West J Med. 1996, 165:43-51.

6. Hollinshead WH. Anatomy for surgeons. 3rd ed. Philadelphia: JB Lippincott, 1982;220-50.

7. Marzo JM, Simmons EH, Kallen F. Intradural connections between adjacent cervical spinal roots. Spine. 1987, 12: 964-8.

8. Tanaka N, Fujimoto Y, An HS, et al. The anatomic relation among the nerve roots, intervertebral foramina, and intervertebral discs of the cervical spine. Spine (Phila Pa 1976). 2000, 25:286-91.

9. Veleanu C. Contributions to the anatomy of the cervical spine. Functional and pathogenetic significance of certain structures of the cervical vertebrae. Acta Anat (Basel). 1975, 92:467-80.

10. Ebraheim NA, An HS, Xu R, et al. The quantitative anatomy of the cervical nerve root groove and the intervertebral foramen. Spine. 1996, 21: $1619-23$.

11. Yilmazlar S, Kocaeli H, Uz A, et al. Clinical importance of ligamentous and osseous structures in the cervical uncovertebral foraminal region. Clin Anat. 2003, 16:404-10.

12. Jiang SD, Jiang LS, Dai LY. Cervical spondylotic amyotrophy. Eur Spine J. 2011, 20:351-7.

13. Zhang J, Cui C, Liu Z, et al. Predisposing factors for poor outcome of surgery for cervical spondylotic amyotrophy: a multivariate analysis. Sci Rep. 2016, 19, 6:39512.

14. Jin X, Jiang JY, Lu FZ, et al. Electrophysiological differences between Hirayama disease, amyotrophic lateral sclerosis and cervical spondylotic amyotrophy. BMC Musculoskelet Disord. 2014, 16;15:349.

15. Kubo Y, Waga S, Kojima T, et al. Microsurgical anatomy of the lower cervical spine and cord. Neurosurgery. 1994, 34:895-900.

16. Karatas A, Caglar S, Savas A, et al. Microsurgical anatomy of the dorsal cervical rootlets and dorsal root entry zones. Acta Neurochir (Wien). 2005, 147:195-199.

17. Shinomiya K, Okawa A, Nakao K, et al. Morphology of C5 ventral nerve rootlets as part of dissociated motor loss of deltoid muscle. Spine. 1994, 19:2501-2504.

18. Kobayashi R, lizuka $H$, Nishinome $M$, et al. A cadaveric study of the cervical nerve roots and spinal segments. Eur Spine J. 2015, 24: 2828-31.

\section{Figures}




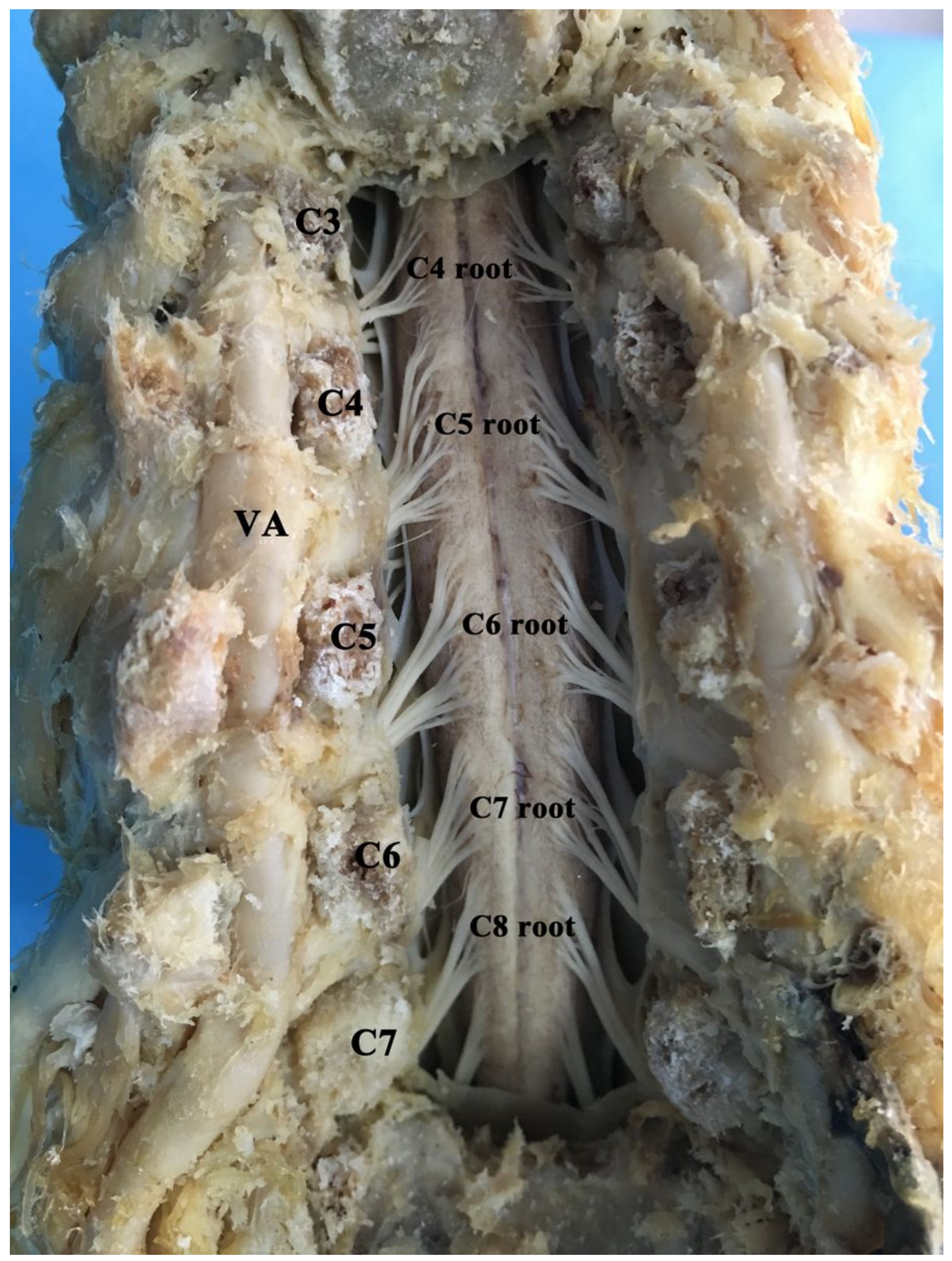

\section{Figure 1}

An example image of a cadaveric specimen showing the spinal cord and ventral nerve rootlets from $\mathrm{C} 4$ to C8. VA: vertebral artery. 


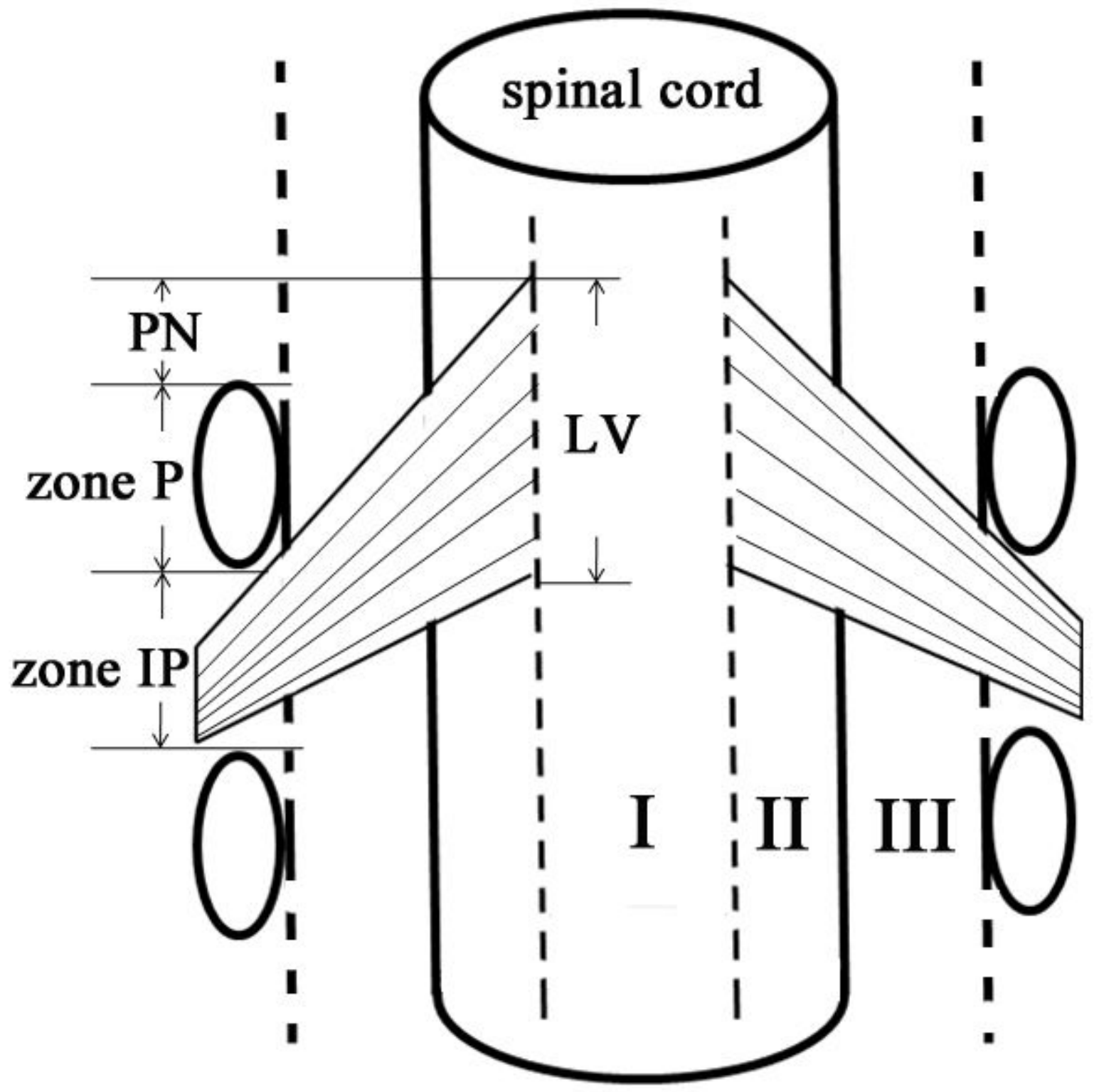

Figure 2

Zone division of the cervical spinal canal. Zone I represents the area between bilateral origins of ventral nerve rootlet. Zone II contains the area between the origin of ventral nerve rootlets and lateral border of spinal cord. Zone III represents the area between lateral border of spinal cord and medial margin of the pedicle. Zone P defines the area between the upper and lower margins of the corresponding pedicle. Zone IP includes the area between the lower margin of the upper pedicle and the upper margin of the lower pedicle. LV, length of the segmental ventral rootlets. PN, the distance between the superior margin of pedicle and the exit of the uppermost ventral nerve rootlet. 

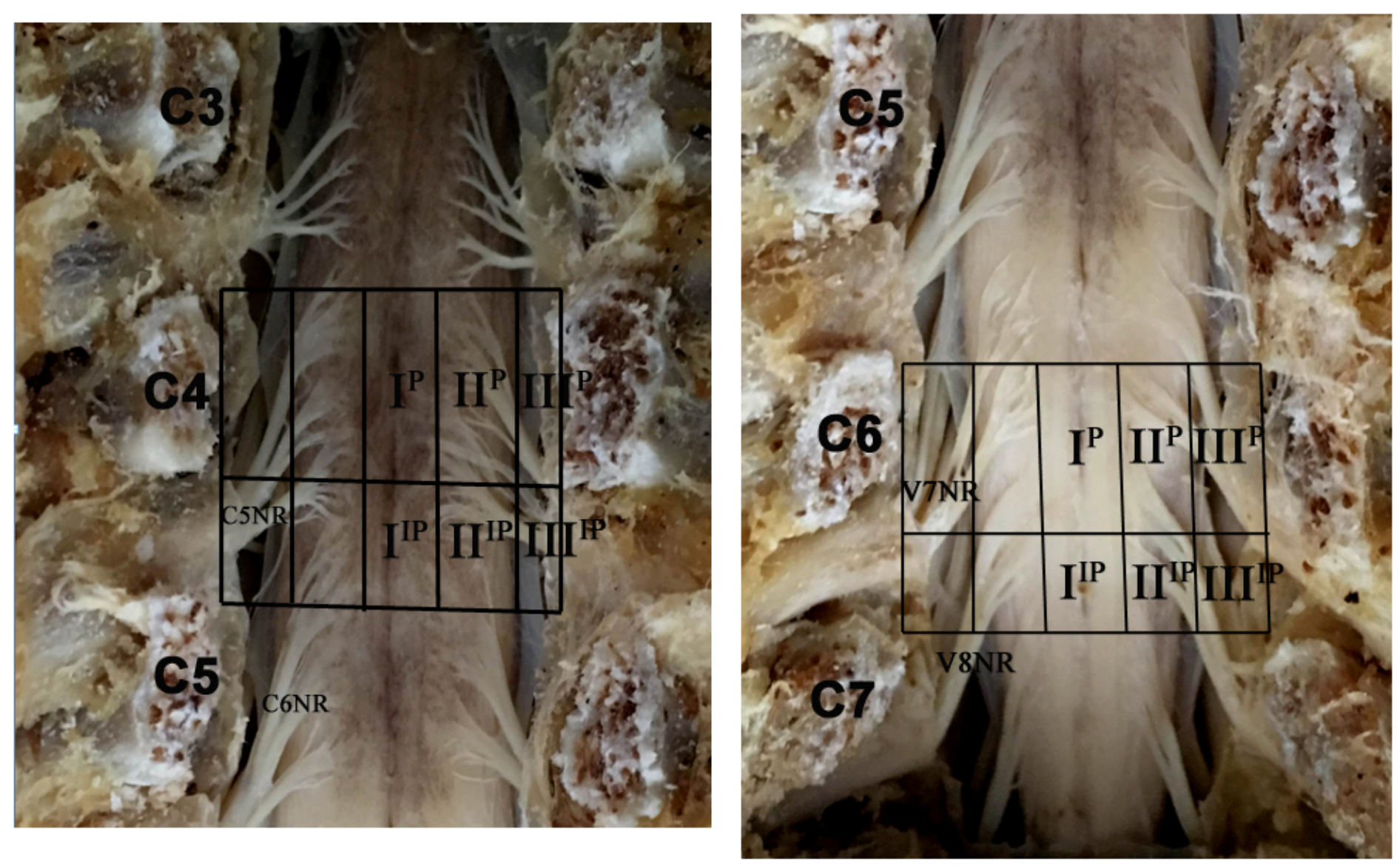

\section{Figure 3}

Example of zone division at cervical segments. a, At C4/5 level, all C6 nerve rootlets were located at zone IP, and zone III contains only C5 nerve rootlets. b, At C6/7 level of the same specimen, part of C8 nerve rootlets reaches zone $\mathrm{P}$, zone III contains both $\mathrm{C7}$ and C8 nerve rootlets. 

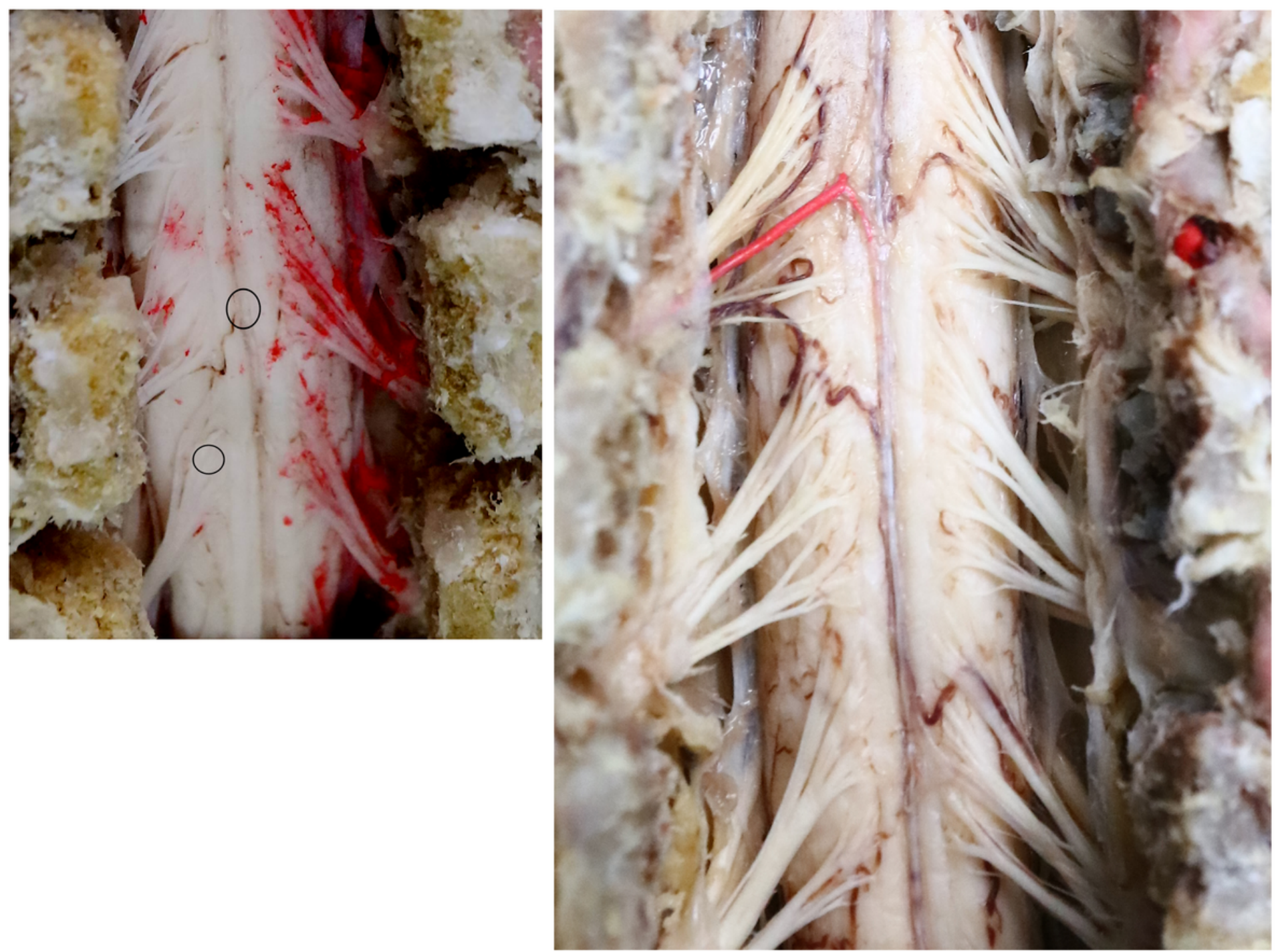

Figure 4

a, The upper black circle shows the compression region in zone I, and the lower black circle shows the compression in zone II. b, Intact cervical spinal cord without any compression. 

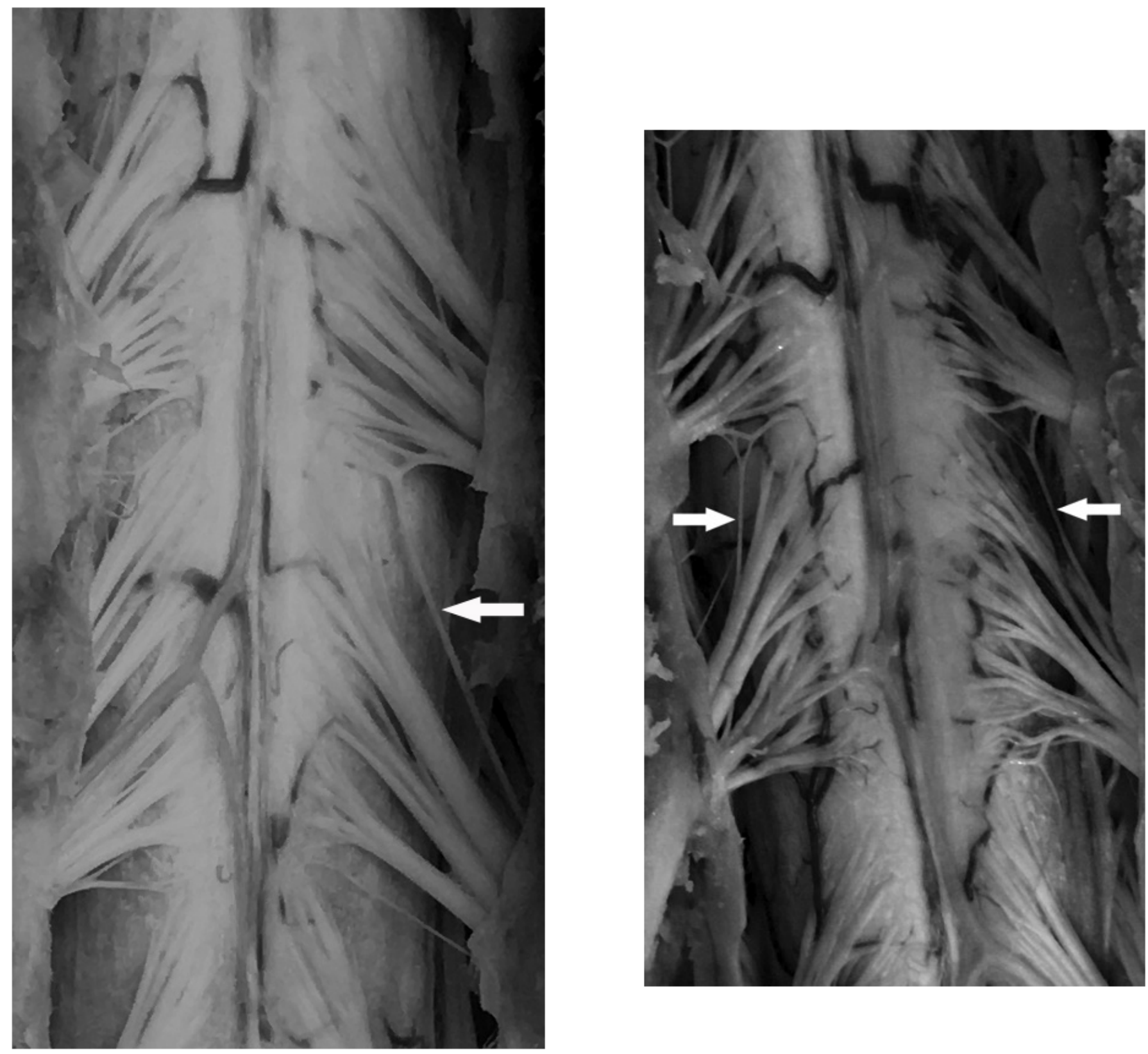

\section{Figure 5}

a, Unilateral intradural intersegmental connection between C5 and C6. b, Bilateral intradural intersegmental connections between C5 and C6. 